\title{
Improved Dissolution and Bioavailability of Eprosartan Mesylate Formulated as Solid Dispersions using Conventional Methods
}

\author{
Pankaj Vijay Dangre*, Mangesh Dinanath Godbole, Priyanka Vijay Ingale, Debarshi Kar Mahapatra
}

Department of Pharmaceutics, Kamla Nehru College of Pharmacy, Nagpur, Maharashtra, INDIA.

\begin{abstract}
Background: Eprosartan mesylate (EM) is a poorly aqueous soluble drug belonging to BCS-class II suffers from low bioavailability (13\%). The present study involves an effort for improving dissolution and thus the bioavailability of EM using solid dispersion approach. Methods: Solid dispersion (SD) was prepared by melting, solvent evaporation and kneading method using different ratios of drug and polymers (PEG-4000, Eudragit E-100, PVP K-30, Poloxamer-407, and Eudragit L-100). Phase solubility study revealed highest solubility in PVP K-30 at 1:2 ratios. The solid state characterizations of selected solid dispersion formulation (SD-15) were performed by infrared spectroscopy, differential scanning calorimeter, $\mathrm{X}$-ray diffraction study and scanning electron microscopy. In vitro dissolution was carried out in phosphate buffer $(\mathrm{pH} \mathrm{7.4)}$ at $50 \mathrm{rpm}$ in $900 \mathrm{ml}$ of volume. The in vivo pharmacokinetic study of selected formulation (SD-15) was carried out in male Wistar rats using non-compartment analysis by linear trapezoidal method after a single oral dose of $10 \mathrm{mg} / \mathrm{kg}$ of EM. Results: The solid state characterization revealed no such drug-polymer interactions and rapid transformation of crystalline drug in an amorphous state, which amplifies the aqueous solubility and hence the dissolution rate. The in vitro dissolution study of the dispersions prepared by PVP K-30 (1:2) was found to be $95.5 \%$ after $1 \mathrm{hr}$. In vivo pharmacokinetic study in Wistar rats showed significant improvement in oral bioavailability of EM in SD-15 with the 2.4 fold increments than the pure drug. Conclusion: The solid dispersion prepared using PVP K-30 by kneading method showed improved dissolution and bioavailability. Therefore, solid dispersion formulation can be sorted as a promising approach for improving the dissolution and bioavailability of Eprosartan mesylate.
\end{abstract}

Key words: Eprosartan mesylate, Solid dispersion, Dissolution, Bioavailability, Characterization.

\section{INTRODUCTION}

Eprosartan mesylate (EM), chemically (E)4-(\{2-Butyl-5-2-carboxy-2-(thiophen-2ylmethyl) eth-1-en-1-yl-1H-imidazol-1-yl methyl) benzoic acid is an anti-hypertensive drug which prevents the vasoconstrictor and aldosterone-secreting effects of angiotensin II by selectively blocking the binding of angiotensin II to the $\mathrm{AT}_{1}$ receptor in vascular smooth muscle. ${ }^{1}$ EM belongs to the class of BCS-II that demonstrate incomplete absorption from the gastrointestinal tract after oral administration and exhibit biological half life of 5-9 hr. ${ }^{2,3}$ EM exhibits $\mathrm{pH}$ dependent aqueous solubility and lipophilicity which may result in variable absorption as the compound passes through the gastrointestinal tract. ${ }^{4}$ Due to extensive hepatic first pass metabolism in the liver and very low solubility, the resultant bioavailability lies about $13 \% .^{5}$ Therefore, a high dose of $800 \mathrm{mg}$ is often prescribed
Submission Date : 26-04-2016 Revision Date : 20-06-2016 Accepted Date : 29-06-2016

DOI: 10.5530/ijper.50.3.31 Correspondence: Pankaj V. Dangre, Assistant Professor, Department of Pharmaceutics, Kamla Nehru College of Pharmacy, Nagpur, Maharashtra, INDIA. Phone no: +91-9960160479 E-mail: pankaj_dangre@ rediffmail.com

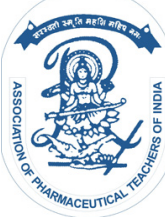

www.ijper.org 
for the management of hypertension and other cardiac complications, which often precipitates adverse or sideeffects. EM bounds extensively with plasma proteins $(98 \%)$ and having a mean terminal elimination halflife of $20 \mathrm{hr}$ at $600 \mathrm{mg}$ oral dose. ${ }^{6}$ EM undergoes little metabolism by oxidative and hydrolytic processes and about $90 \%$ of unchanged drug gets eliminated in feces. The roles of $\mathrm{CYP}_{450}$ isoenzyme forms in drug metabolic processes are quite limited. The metabolized products are very minute and are generally inactive. ${ }^{7}$

Poorly water-soluble drugs involve many difficulties in the development of pharmaceutical dosage forms for oral delivery systems due to their low bioavailability. ${ }^{8}$ During the past few years, there has been a great pace in using solubility enhancement techniques for the improvement of the dissolution rate and subsequently the bioavailability of poorly water soluble drugs. Several techniques like nanomaterialization, ${ }^{9}$ salt formation, ${ }^{10}$ hydrotropy, ${ }^{11}$ liposome formation, ${ }^{12}$ liquisolid compaction, ${ }^{13}$ solid dispersion, ${ }^{14}$ SMEDDS, ${ }^{15}$ and many other significant techniques have been reported for improving bioavailability of poorly water soluble drugs of class BCS-II and BCS-IV.

Solid dispersion (SD) is one of the most promising strategies to improve the dissolution properties and bioavailability of poorly water-soluble drugs where drug materials are dispersed in an inert carrier. ${ }^{16}$ The drug dispersed in polymeric carriers may achieve the highest levels of particle size reduction, surface area enhancement and may exist in amorphous form in polymeric carriers, which results in improved solubilities and dissolution rates as compared with crystalline material. ${ }^{17},{ }^{18}$ In these $\mathrm{SDs}$, no energy is required to break up the crystal lattice of a drug during the dissolution process which produced faster release and higher bioavailability than conventional formulations of the same drugs owe to their small particle size and better wettability of the drug. ${ }^{19}$

The objective of the present study was; (1) to improve the solubility of poorly soluble EM using SD method employing various polymers (PEG-4000, Eudragit E-100, PVP K-30, Poloxamer-407, and Eudragit L-100); (2) to perform solid state characterization of selected EM SD using various approaches like IR, DSC, XRD, and SEM; and (3) to carry out a pharmacokinetic study of the optimized SD formulation of EM.

\section{MATERIALS AND METHODS}

\section{Materials}

EM was obtained as a generous gift from Mylan Laboratories Ltd., Nashik, India. PEG-4000, Eudragit
E-100, PVP K-30, Poloxamer-407, and Eudragit L-100 were obtained from Colorcon Asia Pvt. Ltd., Mumbai, India, and Himedia Ltd., India. HPLC grade acetonitrile and orthophosphoric acid were purchased from Merck Chemicals Ltd., Mumbai, India. Double distilled water was used and was suitably filtered through $0.45 \mu \mathrm{m}$ filter. Miscellaneous ingredients used in the study were of analytical/pharmaceutical grade.

\section{Methods}

\section{Drug content estimation}

The SDs equivalent to $10 \mathrm{mg}$ of EM were accurately measured and dissolved in $10 \mathrm{~mL}$ of phosphate buffer $(\mathrm{pH} 6.8$ and 7.4). The absorbances were recorded at $231 \mathrm{~nm}$ using a UV spectrophotometer (UV-1800, Shimadzu, Japan).

\section{Solubility studies}

An excess quantity of EM was placed in empty reaction tubes (Hi-media, India) containing $2 \mathrm{ml}$ of phosphate buffer (6.8 and 7.4). The tubes were sonicated (Transonic Digital S, USA) for 10 minutes at $25^{\circ} \mathrm{C}$ and the reactant mixture was stirred vigorously using a vortex mixer (V-Mixer Scientific, India) for 5 min to facilitate solubilisation of EM in solvent. The reactant mixture was further agitated continuously on a rotary shaker cum incubator (MVTEX, India) at $40^{\circ} \mathrm{C}$ for $24 \mathrm{hr}$. After reaching equilibrium, the undissolved $\mathrm{EM}$ content in solvent was separated by centrifuging at 10,000 rpm for 5 min and clear supernatants obtained were filtered, suitably diluted and analyzed spectrophotometrically at $231 \mathrm{~nm}$.

\section{Phase solubility study}

The phase solubility studies were carried out according to the method reported by Higuchi and Connors. ${ }^{20}$ An excess amount of EM was added to the screw capped vials containing $20 \mathrm{ml}$ of an aqueous solution of hydrophilic polymers (PEG-4000, Eudragit E-100, PVP K-30, Poloxamer-407, and Eudragit L-100) at various concentrations $(5-100 \mathrm{mM})$ placed in an orbital shaking incubator and agitated for $24 \mathrm{hr}$ at $37^{\circ} \mathrm{C}$. After reaching the equilibrium, the supernatant solutions were filtered suitably by Whatman filter paper (No. 41) and after appropriate dilution; solutions were analyzed by UV spectroscopy at $231 \mathrm{~nm}$.

\section{Preparation of solid dispersions (SDs)}

$\mathrm{SD}$ is one of the most commonly used techniques to improve the solubility of water insoluble drugs which in turn improves the bioavailability. ${ }^{21} \mathrm{EM}$ is practically insoluble moiety belonging to the BCS-II class. Therefore, 
SDs of EM were prepared by hot melt method, solvent evaporation method and kneading method. In hot melt method, the insoluble drug is dispersed into a molten carrier and cooled immediately. In solvent evaporation method, both drug and the carrier were dissolved in a common volatile solvent, and the solvent was evaporated to get SDs. In the kneading method, both insoluble drug and carrier are kneaded and solid damp mass is formed which is further dessicated to obtain SDs.

\section{Melting method}

The melting process was performed as per the method described by $\mathrm{Yu}$ et al. ${ }^{22}$ The carriers; PEG- 4000 and Poloxamer-407 were taken separately in different ratios $(1: 1,1: 1.5,1: 2)$ and heated at $50-55^{\circ} \mathrm{C}$ using a hot plate. The required amount of EM was added in portions to the molten mass of PEG-4000 and Poloxamer-407 separately with continuous stirring using a magnetic stirrer to get the solid mass. The resulting SDs were subsequently desiccated under vacuum for $24 \mathrm{~h}$. The dried mass, then pulverized and passed through sieve No. 80 and were stored in tightly closed container until further study.

\section{Solvent evaporation method}

The solvent evaporation process was performed as per the method described by Sethia and Squillante. ${ }^{23}$ The drug and carriers; Eudragit E-100 and Eudragit L-100 were taken separately in different ratios $(1: 1,1: 1.5$, 1:2) and transferred in a beaker containing appropriate amounts of ethanol (solvent). Subsequently, the solvent was removed by evaporation on magnetic stirrer with hot plate at temperature $40^{\circ} \mathrm{C}$ for $1 \mathrm{hr}$ to get SD mass. The resultant dispersions were pulverized in a mortar and passed through sieve No.80 and desiccated under vacuum for $24 \mathrm{hr}$ and finally stored in tightly closed containers.

\section{Kneading method}

The kneading process was performed as per the method described by Maulvi et al. ${ }^{24}$ The drug and carriers (Eudragit E-100 and Eudragit L-100) were taken in different ratios $(1: 1,1: 1.5,1: 2)$ and mixed well with sufficient quantity of ethanol to produce a solid damped mass. The solid masses were kneaded thoroughly for $30 \mathrm{~min}$ in glass mortar and desiccated under vacuum for $24 \mathrm{hr}$. Finally, the SDs were pulverized and passed through sieve No. 80 and stored in tightly closed containers.

Pharmacokinetic study

The pharmacokinetic study of optimized SD was performed and compared with the standard EM. Wistar male rats aged 5-6 weeks, average weight 225-255 gm, housed in clean polypropylene cages with free access to water and standard rodent pellets were used for the study after approval by the Departmental Animal House Facility with permission of the Department Ethical Committee and CPCSEA (KNCOP/R\&D/ AN-PROT/14-15/02) of Kamla Nehru College of Pharmacy. The pharmacokinetic study for EM SDs was performed as per the method described by Dangre and Dhole. ${ }^{25}$ The rats were fasted overnight before the dosing with free access to water. The rats were divided into two treatment groups $(n=3)$ and each were treated with standard EM and selected SD. EM SD prepared from PVP K-30 (1:2) was suspended in 0.5\% sodium carboxyl methyl cellulose and administered to rats by oral gavage $(10 \mathrm{mg} / \mathrm{kg})$. After oral administration, blood samples of $0.5 \mathrm{ml}$ were collected from the retro-orbital plexus at $0.5,1,2,4,6,8,12$, and $24 \mathrm{hr}$. Plasma was separated from each blood sample by centrifugation at $10,000 \mathrm{rpm}$ for $10 \mathrm{~min}$ and stored at $-20^{\circ} \mathrm{C}$ until analysis. Aliquots of $100 \mu \mathrm{L}$ samples were processed by single step protein precipitation method where $100 \mu \mathrm{L}$ of the drug spiked plasma sample was pipetted into a heparinized centrifuge tube. The plasma was then deproteinized, to free the bound EM, using acetonitrile with a ratio of $1: 3(\mathrm{v} / \mathrm{v})$ acetonitrile: plasma. The plasma: acetonitrile mixtures were vortex mixed for 3 min and then centrifuged at $5,000 \mathrm{rpm}$ for $5 \mathrm{~min}$. The clear supernatant samples were collected and injected into the HPLC system to analyze the EM concentrations. The HPLC system comprised of Shimadzu LC-2010 CHT (Japan) model with SPD 20-AD UV-visible detector. The chromatographic separation was performed on Phenomenox $\mathrm{C}_{18}(250 \times 4.6$ $\mathrm{mm}$ i.d., particle size $5 \mu \mathrm{m}$ ) column. The mobile phase consisting of acetonitrile: water $(45: 55 \% \mathrm{v} / \mathrm{v})$ with $\mathrm{pH}$ 3.4 adjusted with orthophosphoric acid $(85 \% \mathrm{v} / \mathrm{v})$, at a flow rate of $1 \mathrm{~mL} / \mathrm{min}$ was selected. The pharmacokinetic parameters were calculated from measured EM plasma concentrations versus time profile using a non-compartment model with a linear trapezoidal method by PK Solver 2.0 software.

\section{Characterization of solid dispersions}

Solid state characterization was performed for drug, polymers and selected SDs.

Infrared spectral analysis

IR absorption spectrum (FTIR spectrophotometer, GX-FT-IR, Perkin Elmer, USA) of EM (pure drug) and selected formulations of SDs were recorded by potassium bromide dispersion technique in the range of $4000-400 \mathrm{~cm}^{-1}$. The compounds were scanned at a resolution of $0.15 \mathrm{~cm}^{-1}$ and scan speed was $20 \mathrm{scan} / \mathrm{s}$. 


\section{Differential scanning calorimeter analysis}

The physical state of EM and selected formulation of SDs was characterized by differential scanning calorimeter (DSC) thermogram analysis. The DSC patterns were recorded on a Pyris Diamond TG/DTA Perkin Elmer. Each sample was heated in a platinum crucible along with alpha alumina powder as a reference at a scanning rate of $10^{\circ} \mathrm{C} / \mathrm{min}$ in an atmosphere of nitrogen $(150$ $\mathrm{mL} / \mathrm{min}$ ) using the range of $30-300^{\circ} \mathrm{C}$. The temperature calibrations were performed periodically using indium as a standard.

\section{X-ray Diffraction analysis}

The physical state of EM and SDs formulations was characterized by X-ray powder scattering (XRD) measurements using X-ray diffractometer (ULTIMA-III, RIGAKU, Japan). The measurements were performed at room temperature using monochromatic $\mathrm{CuK}$ - radiation (Cu target, slit $10 \mathrm{~mm}$ ) at $40 \mathrm{KV}$ over a range of 7 to 80 with a continuous scanning speed of $4 / \mathrm{min}$. The analyzed sample was compactly packed in the cavity of an aluminium sample holder using a glass slide.

\section{Scanning electron microscopy analysis}

The external morphology of the EM and selected formulation of SDs was studied by scanning electron microscopy (SEM). The samples for SEM were prepared by slightly sprinkling powder on a double adhesive tape stuck to an aluminium stub. Afterwards, the stub containing the coated samples was placed in the scanning electron microscope (SEM) chamber. The samples were then randomly scanned and photomicrographs were taken at the acceleration voltage of $10 \mathrm{kV}$ and the result of SEM was reported.

\section{In vitro dissolution study}

The in vitro dissolution study of pure drug and SDs were performed using dissolution test apparatus USP 33 (Type II) apparatus in $900 \mathrm{ml}$ of dissolution medium containing sodium lauryl sulfate $(0.5 \%)$ in simulated gastric fluid without enzyme, $\mathrm{pH} 7.4$ maintained at $37 \pm 0.5^{\circ} \mathrm{C}$ at a speed of $50 \mathrm{rpm}$. The pure drug and SDs equivalent to $400 \mathrm{mg}$ of EM were separately placed in dissolution medium. From each vessel at specific time interval, $1 \mathrm{ml}$ of sample was withdrawn, filtered through Whatman filter paper (No.41), diluted and analyzed spectrophotometrically (Shimadzu UV-1800, Kyoto, Japan) at $231 \mathrm{~nm}$. An equal volume of fresh medium which was prewarmed at $37 \pm 0.5^{\circ} \mathrm{C}$, replaced in the dissolution medium after each sampling to maintain the constant volume throughout the test. The release studies were conducted in triplicate. The data were studied using PCP-Disso v2.08 software.

\section{RESULT AND DISCUSSION}

\section{Drug content}

The drug content was observed in the range of 86.03$93.59 \%$ in phosphate buffer at $\mathrm{pH}$ 6.8, while the drug content was observed in the range of 94.19-99.46\% in phosphate buffer at pH 7.4 using kneading method (Table 1). PVP K-30 displayed the highest; $99.46 \pm$ $0.41 \%$ drug content in 1:2 ratio at $\mathrm{pH} 7.4$, compared to other SDs prepared by fusion method and solvent evaporation method.

\section{Solubility studies}

The solubility studies have revealed that higher saturation solubility $(\mathrm{mg} / \mathrm{mL})$ at $\mathrm{pH} 7.4$ than at $\mathrm{pH}$ 6.8. The saturation solubility was found to be in the range 81.2-153.3 $\mathrm{mg} / \mathrm{mL}$ at $\mathrm{pH}$ 7.4. The kneading method shows better saturation solubility of SDs prepared by using carrier PVP K-30 in the ratio of $1: 2$ in $\mathrm{pH} 7.4$ as compared to fusion method and solvent evaporation method. The increase in the saturation solubility of drug can be explained by improved dissolution of SDs.

Phase solubility study

The plot of EM solubility in PVP K-30 polymer indicated that the solubility gets increased with increasing concentration of the carrier (Figure 1). The plot between EM and PVP K-30 aqueous solution showed the highest phase solubilization as compared to other polymeric solutions.

\section{Infrared spectral analysis}

The FTIR spectrum of drug and SDs are shown in Figure 2. The spectrum of EM (Figure 2a) showed characteristic peaks at 3103 (OH carboxylic), 2873 (alkane stretch), 1710 (C=O stretching), $1647(\mathrm{C}=\mathrm{N}), 1614$ $(\mathrm{C}=\mathrm{C})$, and $1311(\mathrm{C}-\mathrm{N})$, respectively. The spectrum of SD of EM (Figure 2b) exhibited analogous results. The observed prominent peaks are 3103 (OH carboxylic), 1716 (C=O stretching), 2864 (alkane stretch), 1683 $(\mathrm{C}=\mathrm{N}), 1616(\mathrm{C}=\mathrm{C})$, and $1313(\mathrm{C}-\mathrm{N})$, respectively, which are quite similar to the spectrum of EM. This concluded that there were no such drug-polymer interactions in the SDs.

\section{Differential scanning calorimeter analysis}

The DSC thermograms of pure drug (EM) and SD are described in (Figure 3). The drug exhibited sharp endothermic peak at $250.66^{\circ} \mathrm{C}$ with peak onset at $246.18^{\circ} \mathrm{C}$ (Figure 3a), which corresponds to its melting point, thereby confirming the crystalline nature. In contrast, the SD of drug: PVP K-30 in 1:2 ratio demonstrated broad endothermic peak (Figure 3b) over the entire scanning 
Table 1: Drug content and saturation solubility of solid dispersions prepared by various methods

\begin{tabular}{|c|c|c|c|c|c|c|c|}
\hline \multirow{2}{*}{$\begin{array}{l}\text { Batch } \\
\text { Code }\end{array}$} & \multirow{2}{*}{ Solid dispersion system } & \multirow{2}{*}{$\begin{array}{c}\text { Method of } \\
\text { preparation }\end{array}$} & \multirow{2}{*}{$\begin{array}{c}\text { Ratio of } \\
\text { drug: } \\
\text { carrier }\end{array}$} & \multicolumn{4}{|c|}{ Drug content (\%) Saturation solubility } \\
\hline & & & & pH 6.8 & pH 7.4 & pH 6.8 & pH 7.4 \\
\hline SD-1 & Eprosartan : Poloxamer 407 & Melting & $1: 1$ & $86.10 \pm 0.10$ & $94.19 \pm 0.17$ & $64.19 \pm 0.20$ & $81.22 \pm 0.23$ \\
\hline SD-2 & Eprosartan : Poloxamer 407 & Melting & $1: 1.5$ & $88.41 \pm 0.51$ & $94.28 \pm 0.25$ & $68.28 \pm 0.25$ & $93.04 \pm 0.08$ \\
\hline SD-3 & Eprosartan : Poloxamer 407 & Melting & $1: 2$ & $88.87 \pm 0.24$ & $95.33 \pm 0.49$ & $74.35 \pm 0.32$ & $94.18 \pm 0.16$ \\
\hline SD-4 & Eprosartan : PEG 4000 & Melting & $1: 1$ & $86.03 \pm 0.15$ & $95.61 \pm 0.55$ & $59.23 \pm 0.23$ & $92.02 \pm 0.02$ \\
\hline SD-5 & Eprosartan : PEG 4000 & Melting & $1: 1.5$ & $86.10 \pm 0.10$ & $96.07 \pm 0.07$ & $60.39 \pm 0.35$ & $96.31 \pm 0.28$ \\
\hline SD-6 & Eprosartan : PEG 4000 & Melting & $1: 2$ & $89.03 \pm 0.15$ & $96.24 \pm 0.55$ & $63.23 \pm 0.09$ & $102.4 \pm 0.45$ \\
\hline SD-7 & Eprosartan : Eudragit E 100 & SE & $1: 1$ & $84.01 \pm 0.10$ & $94.51 \pm 0.03$ & $58.29 \pm 0.27$ & $103.3 \pm 0.40$ \\
\hline SD-8 & Eprosartan : Eudragit E 100 & SE & $1: 1.5$ & $85.83 \pm 0.55$ & $97.16 \pm 0.15$ & $66.37 \pm 0.02$ & $112.3 \pm 0.20$ \\
\hline SD-9 & Eprosartan : Eudragit E 100 & SE & $1: 2$ & $86.28 \pm 0.30$ & $97.46 \pm 0.04$ & $78.30 \pm 0.54$ & $113.1 \pm 0.25$ \\
\hline SD-10 & Eprosartan : Eudragit L 100 & SE & $1: 1$ & $86.31 \pm 0.33$ & $96.53 \pm 0.40$ & $72.34 \pm 0.31$ & $83.76 \pm 0.09$ \\
\hline SD-11 & Eprosartan : Eudragit L 100 & SE & $1: 1.5$ & $87.34 \pm 0.54$ & $97.32 \pm 0.68$ & $73.01 \pm 0.01$ & $97.48 \pm 0.42$ \\
\hline SD-12 & Eprosartan : Eudragit L 100 & SE & $1: 2$ & $87.95 \pm 1.56$ & $98.51 \pm 0.54$ & $74.02 \pm 0.05$ & $101.6 \pm 0.49$ \\
\hline SD-13 & Eprosartan : PVP K-30 & Kneading & $1: 1$ & $90.15 \pm 0.21$ & $98.33 \pm 0.33$ & $79.22 \pm 0.20$ & $99.37 \pm 0.32$ \\
\hline SD-14 & Eprosartan : PVP K-30 & Kneading & $1: 1.5$ & $93.59 \pm 0.52$ & $99.10 \pm 0.10$ & $77.53 \pm 0.49$ & $129.0 \pm 0.05$ \\
\hline SD-15 & Eprosartan : PVP K-30 & Kneading & $1: 2$ & $92.10 \pm 0.53$ & $99.46 \pm 0.41$ & $75.45 \pm 0.50$ & $153.3 \pm 0.28$ \\
\hline SD-16 & Eprosartan : Eudragit L 100 & Kneading & $1: 1$ & $89.62 \pm 1.67$ & $95.06 \pm 0.13$ & $63.20 \pm 0.18$ & $93.42 \pm 0.13$ \\
\hline SD-17 & Eprosartan : Eudragit L 100 & Kneading & $1: 1.5$ & $90.96 \pm 0.30$ & $96.49 \pm 0.44$ & $77.48 \pm 0.45$ & $95.68 \pm 0.05$ \\
\hline SD-18 & Eprosartan : Eudragit L 100 & Kneading & $1: 2$ & $93.08 \pm 0.11$ & $98.20 \pm 0.27$ & $77.70 \pm 1.88$ & $122.5 \pm 0.53$ \\
\hline D & Pure drug & - & - & - & - & $15.33 \pm 0.29$ & $48.53 \pm 0.47$ \\
\hline
\end{tabular}

$\mathrm{SE}$, solvent evaporation

\begin{tabular}{|c|c|c|}
\hline $\begin{array}{l}\text { Pharmacokinetic } \\
\text { Parameters }\end{array}$ & Drug in suspension & SD-15 \\
\hline$A \cup C_{0-t}\left(n g / m L^{*} h\right)$ & $2679.4 \pm 421.2$ & $6627.6 \pm 256.4$ \\
\hline$A \cup C_{0-\infty}\left(n g / m L^{*} h\right)$ & $3637.7 \pm 354.1$ & $8127.6 \pm 367.6$ \\
\hline $\mathrm{C}_{\max }(\mathrm{ng} / \mathrm{mL})$ & $924 \pm 24.3$ & $2147.34 \pm 27.3$ \\
\hline $\mathrm{T}_{\max }(\mathrm{h})$ & $2.0 \pm 0.0$ & $1.5 \pm 0.0$ \\
\hline$t_{1 / 2}(h)$ & $6.49 \pm 0.4$ & $7.6 \pm 0.8$ \\
\hline Relative bioavailability & - & 2.4 \\
\hline \multicolumn{3}{|c|}{$\begin{array}{l}\text { SD-15, solid dispersion prepared with PVP K-30, AUC } C_{0-t}-\text { area under the concentration time } \\
\text { profile curve until last observation, } A \cup C_{0-\infty}-- \text { area under the concentration time profile curve } \\
\text { extrapolated to infinity, } C_{\max } \text { - peak of maximum concentration, } T_{\max } \text { - time of peak concentration, } \\
\mathrm{t}_{1 / 2} \text { - elimination half life. }\end{array}$} \\
\hline
\end{tabular}

range of $30^{\circ} \mathrm{C}-300^{\circ} \mathrm{C}$, suggesting rapid transformation into amorphous nature. Thus, it may be concluded that no such characteristic pure drug peak indicated the change in melting behaviour of drug and inhibition of crystallization since amorphous state is considered as a state of high disorder, the solid particles present remain in highly dissolved state. However, Figure $3 \mathrm{~b}$ shows an endothermic peak whose onset temperature approximately coincides with that for the endothermic peak of (Figure 3a). The probable reason may be that in solid dispersions, the endothermic peak gets broadened and shifted toward low temperature which may be due to the higher polymeric concentrations and distribution of drug in the polymer layer causing the entire molten drug to be miscible in the polymer core. ${ }^{26}$

\section{Powder X-ray Diffraction analysis}

Powder-X-ray diffraction (P-XRD) study provides information of the crystalline nature of drugs and reveals the possible arrangement of atoms inside the crystal lattice. The appearance of several intense crystalline peaks reflects the existence of EM in crystalline 


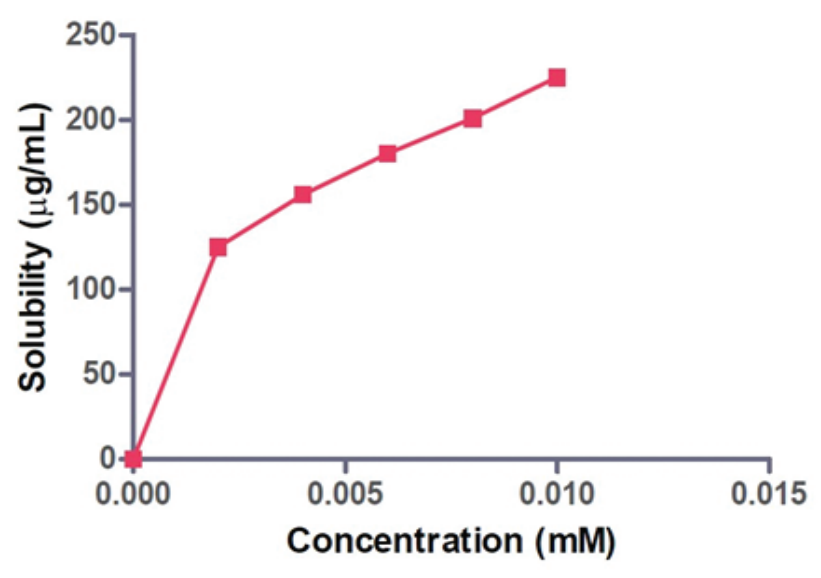

Figure 1: Phase solubility plot of eprosartan mesylate in PVP K-30.
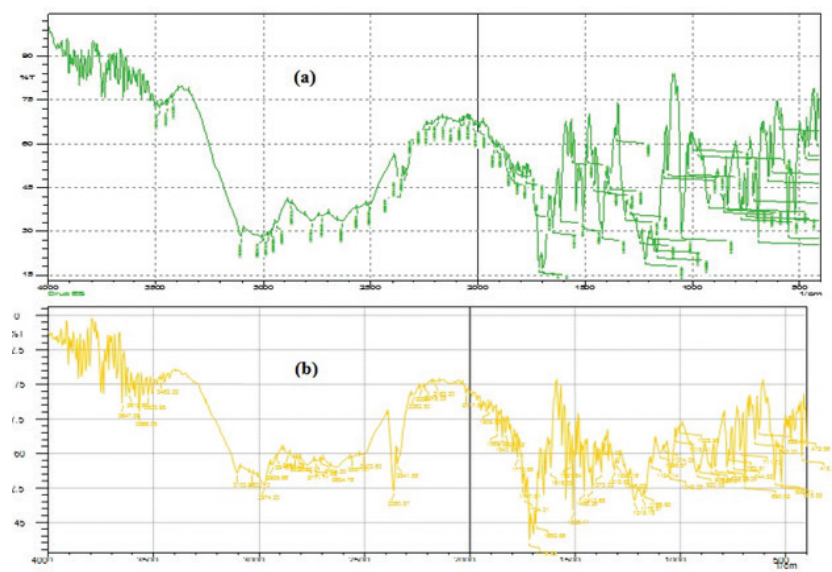

Figure 2: Fourier transfer infrared spectra (FTIR) of eprosartan mesylate (pure drug) and solid dispersion (SD-15).
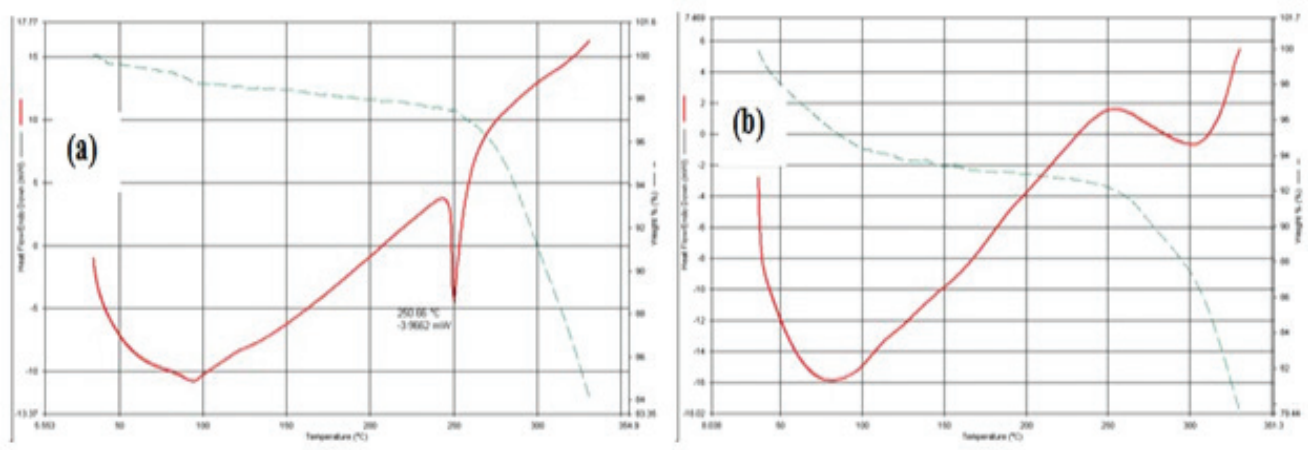

Figure 3: Differential scanning calorimetric thermogram: (A) Eprosartan mesylate (pure drug), (B) Solid dispersion formulation (SD-15).
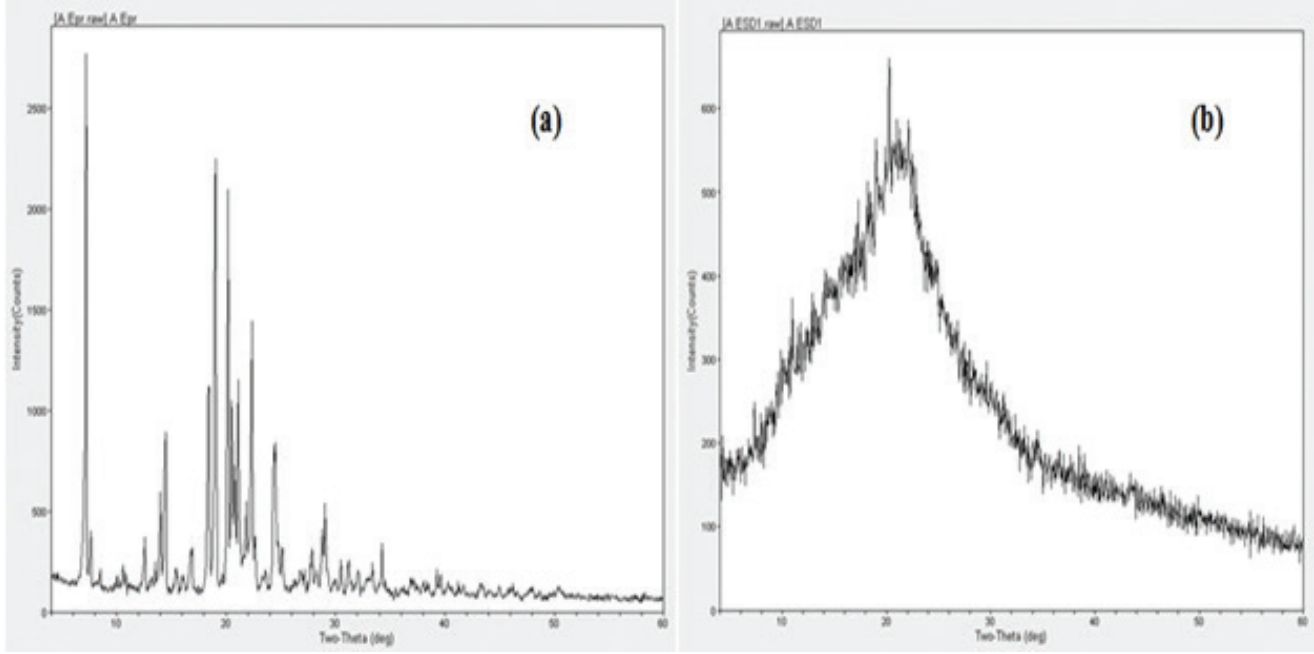

Figure 4: Powder X-ray diffraction spectra of (A) Pure drug of EM, (B) Solid dispersion formulation (SD-15). 

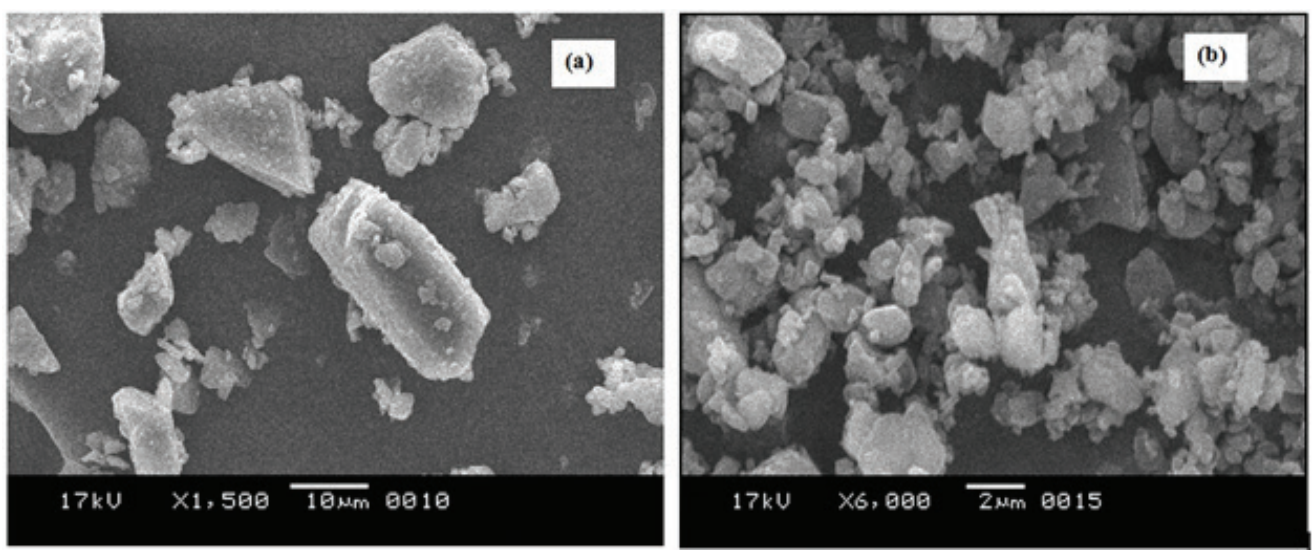

Figure 5: Scanning electron micrograph; (a) Eprosartan mesylate (pure drug); (b) Solid dispersion formulation (SD-15).

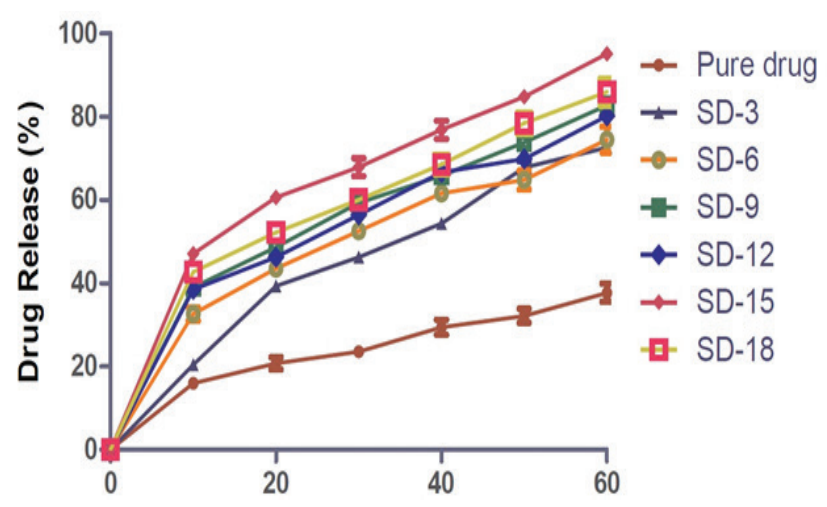

Figure 6: In vitro dissolution profile of pure drug of eprosartan mesylate and solid dispersion

formulation prepared with 1:2 (drug: polymer ratio) (Mean \pm $\mathrm{SD} ; \mathrm{n}=3)$.

state (Figure 4a). However, an analysis of PXRD pattern of SDs (Figure 4b) depicted no such significant peaks which stalwartly confirmed the molecularly dispersed state of EM in the formulation and effective solubilisation of the drug. In formation of SDs, the drug experienced swift renovation from crystalline state to its amorphous form, which is having high internal energy, thereby resulting in prompt dissolution of drug materials as compared to its crystalline forms.

\section{Scanning electron microscopy analysis}

The surface morphology of pure drug (EM) and SD were investigated using scanning electron microscope (SEM) and their micrographs are shown. Pure EM appeared as rod shaped crystals having a very rough surface (Figure 5a). In contrast, the photomicrograph of surface SD (Figure $5 b$ ) indicated the uniform surfaces, smooth particle with aggregated spherical particles and deep crevices. This suggested that entire drug was distributed uniformly in the carrier mass and represented well separated particles.

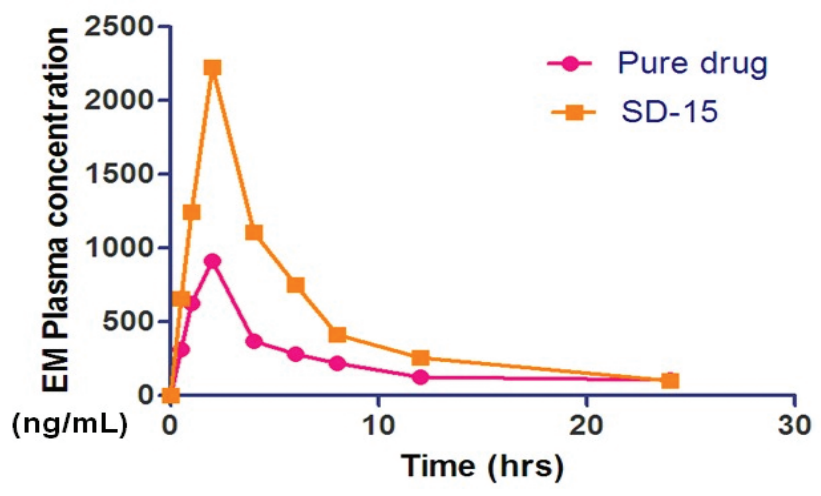

Figure 7: The mean plasma concentration vs. time profile of pure drug and selected solid

dispersion formulation (SD-15) in rats after oral administration (Mean $\pm S D, n=3)$.

\section{In vitro dissolution}

The in vitro drug release profile of SDs were studied and compared with the pure drug of EM (Figure 6). In all the SDs prepared by different methods, the SDs with 1:2 ratios (drug: polymer) exhibited higher drug content as well as maximum saturation solubility of the drug. Therefore, the SDs prepared with 1:2 ratios were employed for drug release study. Among all the batches, the dispersion prepared by kneading, using PVP K-30 (SD-15) showed a better drug release profile. The improvement in dissolution rate was also observed in all the formulations of SDs prepared by solvent evaporation and melting method using Polaxamer-407, PEG-4000, Eudragit L100, and Eudragit E 100. The results suggest significant improvement in dissolution of SDs prepared by kneading method using PVP K-30 $(95.5 \%)$. The SDs prepared with higher ratios of polymer could offer more available space for surrounding of hydrophobic drug particle resulted in rapid hydration of drug molecules and consequently better wettability 
and enhancement in the dissolution. Moreover, the transformation of the crystalline nature of pure EM into the amorphous form as affirmed by the DSC and PXRD results facilitates higher drug release rate over the pure drug. As shown in (Figure 6), the SDs prepared by kneading method using PVP K-30 was found to be superior and simple over the other conventional methods of SDs.

The reason for the superior dissolution by kneading method may be attributed due to better reduction of particle size and promotion of amorphous nature to the drug resulting in improved release and enhanced exposed surface area promoting higher dissolution. In the binary state, drug particles lie in contact with the polymeric phase. When the drug and polymer comes in contact with aqueous phase, the polymeric units get hydrated into its solution state, which consequently promote solubilization of the drug causing release of drug into the media. At low concentration of polymers, monomolecular micelles are formed which endorse dissolution of drug in media, as the concentration increases, the micelles aggregate to form multimolecular micelles which solubilizes the drug to still high extent. ${ }^{27}$ The ratio of the free drug concentration to the crystalline equilibrium solubility, can also be used to define the supersaturation. The inhibition of crystallization during dissolution enables supersaturated solution to be generated under non-sink dissolution conditions. A solution with a free drug concentration below the crystalline solubility has a supersaturation $<1$ and will not crystallize. In contrast, a solution with a free drug concentration greater than the crystalline solubility has a supersaturation $>1$, and a thermodynamic driving force for crystallization. ${ }^{28}$ The SDs exhibited supersaturated solution owing to inhibition of crystallization during dissolution with free drug concentration below the crystalline solubility. Both theoretical and practical supersaturation value was found to be $<1$.

Pharmacokinetic study

The in vivo pharmacokinetic parameters of SD-15 and standard EM were studied in Wistar rats. The measured mean EM plasma concentrations versus time after single oral administration in male Wistar rats using $0.5 \%$ oral suspension are depicted in (Figure 7). The pharmacokinetic parameters calculated from the non-compartment model using linear trapezoidal method are described in (Table 2). Relative bioavailability was calculated by using the following formula:

Relative bioavailability $(\%)=\mathrm{AUC}_{\text {test }} / \mathrm{AUC}_{\text {reference }} \times$ Dose $_{\text {reference }} /$ Dose $_{\text {test }}$
The pharmacokinetic parameters of EM, obtained from non-compartmental analysis using a linear trapezoidal method after a single oral dose of $10 \mathrm{mg} / \mathrm{kg}$ of EM to Wistar rats. The $\mathrm{t}_{1 / 2}, \mathrm{~T}_{\max }$ and $\mathrm{C}_{\max }$ of the drug was found to be about $6.49 \mathrm{hr}, 2 \mathrm{hr}$, and $924 \mathrm{ng} / \mathrm{mL}$ respectively along with $\mathrm{AUC}_{0-\mathrm{t}}$ of $2679.4 \mathrm{ng} / \mathrm{mL}^{*}$ h. In contrast, the SD-15 demonstrated higher $\mathrm{C}_{\max }$ and $\mathrm{AUC}_{0-\mathrm{t}}$ as compared to standard drug suspension $\left(\mathrm{C}_{\max }=2147.34 \mathrm{ng} / \mathrm{mL}\right.$, $\left.\mathrm{AUC}_{0-\mathrm{t}}=6627.6 \mathrm{ng} / \mathrm{mL} * \mathrm{~h}\right)$. Conversely, the $\mathrm{T}_{\max }$ of the SD-15 was delayed as compared to the standard EM $\left(\mathrm{T}_{\max }=1.5 \mathrm{hr}\right)$. The relative bioavailability of SD-15 formulation was found to be about 2.4 folds higher, which may be due to conversion of drug into its amorphous form in SDs which is having high internal energy that promotes quick dissolution and hence higher bioavailability was observed (Figure 7).

\section{CONCLUSION}

The current study highlighted a simple method for the fabrication of SDs. The study indicated that the SDs of eprosartan mesylate prepared using PEG-4000, Eudragit E-100, PVP K-30, Poloxamer-407, and Eudragit L-100 have successfully enhanced the solubility of drug which in turn improved the dissolution profile. The nature, type, process, and the amount of the carrier used have played an imperative role in the improvement of dissolution rate. The rapid transformation of crystalline drug to amorphous state and prompt reduction in onset of action by amplifying the aqueous solubility and dissolution rate leads to better bioavailability profile. The dissolution rate of the SDs prepared by PVP K-30 (1:2) with kneading method was observed to be higher than the others prepared by PEG 4000 (1:2), Eudragit L (1:2) and Poloxamer 407 (1:2). The DSC thermogram also suggests that in the kneading process, the drug crystals get dispersed in the carrier and no molecular interactions were observed, suggesting no interaction between the components of two systems. This study opened new doors for therapeutic perspective of EM in coming future.

\section{ACKNOWLEDGEMENT}

Authors are highly thankful to Secretary, Amar Sewa Mandal's Kamla Nehru College of Pharmacy for providing research facilities.

\section{CONFLICT OF INTEREST}

Authors have no conflict of interest with the content of this article. 


\section{REFERENCES}

1. Lemke TL, Williams DA and Foye's Principles of Medicinal Chemistry, sixth ed., Lippincott Williams \& Wilkins, Philadelphia, 2012.

2. Plosker GL. Eprosartan. Drugs. 2009;69(17):2477-99. http://dx.doi.org/10.2165/ 11203980-000000000-00000 ; PMid:19911859.

3. Dangre P, Sawale V, Meshram S, Gunde M. Development and validation of RP-HPLC method for the Simultaneous Estimation of Eprosartan mesylate and chlorthalidone in Tablet Dosage Form. Int J Pharm Tech Res. 2015;8(2):163-8.

4. Arane PM, Ghanwat DA, Boyane V, Kothawade SN and Doshi P. Preparation and in vitro Characterization of Eprosartan Mesylate 658-65. Solid Dispersions using Skimmed Milk Powder as Carrier. Int J Adv Pharm Res. 2011;2(12):658-65

5. Sica DA. Clinical pharmacology of the angiotensin receptor antagonists. J Clin Hypertens. 2001;3(1):45-9. http://dx.doi.org/10.1111/j.1524-6175.2001. 00832.x.

6. Robins GW, Scott LJ. Eprosartan. Drugs. 2005;65(16):2355-77. http://dx.doi. org/10.2165/00003495-200565160-00012 ; PMid:16266204.

7. Ruilope L, Jager B. Eprosartan for the treatment of hypertension. Exp Opin Pharmacother. 2003;4(1):107-14. http://dx.doi.org/10.1517/14656566. 4.1.107 ; PMid:12517247.

8. Dangre PV, Gilhotra RM and Dhole SN. Formulation and development of solid self micro-emulsifying drug delivery system (S-SMEDDS) containing chlorthalidone for improvement of dissolution. J Pharm Investig. DOI 10.107/ s40005-016-0243-2.

9. Anwar M, Warsi MH, Mallick N, Akhter S, Gahoi S, et al Enhanced bioavailability of nano-sized chitosan-atorvastatin conjugate after oral administration to rats. Eur J Pharm Sci. 2011;44(3):241-9. http://dx.doi. org/10.1016/j.ejps.2011.08.001; PMid:21864678.

10. Serajuddin AT. Salt formation to improve drug solubility. Adv Drug Deliv Rev. 2007;59(7):603-16. http://dx.doi.org/10.1016/j.addr.2007.05.010; PMid:17619064.

11. Lee SC, Huh KM, Lee J, Cho YW, Galinsky RE and Park K. Hydrotropic polymeric micelles for enhanced paclitaxel solubility: in vitro and in vivo characterization. Biomacromolecules. 2007;8(1):202-8. http://dx.doi.org/10.1021/ bm060307b; PMid:17206808 PMCid:PMC2532792.

12. Yang T, Cui FD, Choi MK, Cho JW, Chung SJ, et al. Enhanced solubility and stability of PEGylated liposomal paclitaxel: in vitro and in vivo evaluation. International Journal Pharmaceutics 2007;338(1):317-26. http://dx.doi. org/10.1016/j.ijpharm.2007.02.011; PMid:17368984.

13. Javadzadeh $Y$, Siahi MR, Asnaashari S, Nokhodchi A. Liquisolid technique as a tool for the enhancement of poorly water-soluble drugs and evaluation of their physicochemical properties. Acta Pharm. 2007;57(1):99-109. http:// dx.doi.org/10.2478/v10007-007-0008-6 ; PMid:19839410

14. Kumar SD, Bihari GV, Suresh P. Solubility improvement using solid dispersion; Strategy, mechanism and characterization: Responsiveness and prospect way outs. Int Res J Pharm. 2011;2(1):55-60.

15. Patel D, Sawant KK. Oral bioavailability enhancement of acyclovir by selfmicroemulsifying drug delivery systems (SMEDDS). Drug Dev Ind Pharm.

\section{PICTORIAL ABSTRACT}

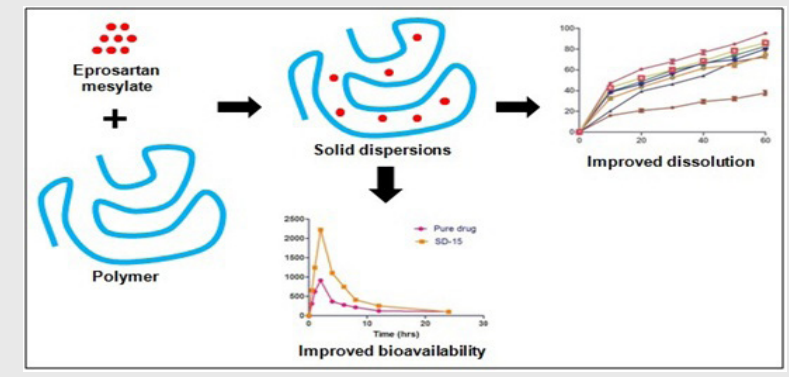

2007;33(12):1318-26. http://dx.doi.org/10.1080/03639040701385527 PMid:18097805.

16. Das SK, Roy S, Kalimuthu Y, Khanam J, Nanda A. Solid dispersions: an approach to enhance the bioavailability of poorly water-soluble drugs. International Journal Pharmacol Pharm Technol. 2012;1(1):37-46.

17. Serajuddin A. Solid dispersion of poorly water-soluble drugs: early promises, subsequent problems, and recent breakthroughs. J Pharm Sci. 1999;88(10):1058-66. http://dx.doi.org/10.1021/js980403I ; PMid:10514356.

18. Vasconcelos T, Sarmento B, Costa P. Solid dispersions as strategy to improve oral bioavailability of poor water soluble drugs. Drug Discov Today. 2007;12(23):1068-75. http://dx.doi.org/10.1016/j.drudis.2007.09.005; PMid: 18061887.

19. Leuner C, Dressman J. Improving drug solubility for oral delivery using solid dispersions. Eur J Pharm Biopharm. 2000;50(1):47-60. http://dx.doi. org/10.1016/S0939-6411(00)00076-X.

20. Higuchi T, Connors KA. Phase-solubility techniques. Adv Anal Chem Instrum. 1965;4:117-212.

21. Huang $Y$, Dai WG. Fundamental aspects of solid dispersion technology for poorly soluble drugs. Acta Pharm Sin B. 2014;4(1):18-25. http://dx.doi. org/10.1016/j.apsb.2013.11.001 ; PMid:26579360 PMCid:PMC4590721.

22. Yu H, Chun MK, Choi HK. Preparation and characterization of piroxicam/ poloxamer solid dispersion prepared by melting method and solvent method. J Pharm Investig. 2007;37(1):1-5. http://dx.doi.org/10.4333/ KPS.2007.37.1.001.

23. Sethia S, Squillante E. Solid dispersion of carbamazepine in PVP K30 by conventional solvent evaporation and supercritical methods. Int J Pharmaceut. 2004;272(1):1-10. http://dx.doi.org/10.1016/j.ijpharm.2003.11.025; PMid:15019063.

24. Maulvi FA, Dalwadi SJ, Thakkar VT, Soni TG, Gohel MC, Gandhi TR. Improvement of dissolution rate of aceclofenac by solid dispersion technique. Powder Tech. 2011;207(1):47-54. http://dx.doi.org/10.1016/j. powtec.2010.10.009.

25. Dangre PV, Dhole SN. Development and Validation of RP-HPLC Method for Determination of Eprosartan Mesylate in Rat Plasma: Application to Preclinical Pharmacokinetic Study. Pharm Methods. 2015;6(2):100-4. http:// dx.doi.org/10.5530/phm.2015.6.14.

26. Modi A, Tayade P. Enhancement of dissolution profile by solid dispersion (kneading) technique. AAPS PharmSciTech. 2006;7(3):E87-92. http://dx.doi. org/10.1208/pt070368; PMid:17025249 PMCid:PMC2750510.

27. Choudhary D, Kumar S. Enhancement of solubility and dissolution of glipizide by solid dispersion (kneading) technique. Asian Journal of Pharmaceutics (AJP): Free full text articles from Asian J Pharm. 2014;3(3):245-91. http:// dx.doi.org/10.4103/0973-8398.56306.

28. Jackson MJ, Kestur US, Hussain MA, Taylor LS. Dissolution of danazol amorphous solid dispersions: supersaturation and phase behavior as a function of drug loading and polymer type. Molecular pharmaceutics. 2015;13(1):223-31. http://dx.doi.org/10.1021/acs.molpharmaceut.5b00652; PMid:2661871.

\section{SUMMARY}

- EM's bioavailability is enhanced by formation of solid dispersions.

- Polymers (PEG-4000, Eudragit E-100, PVP K-30, Poloxamer-407, and Eudragit L-100) are used for formulation.

- Characterization was done by infrared spectroscopy, differential scanning calorimeter, X-ray diffraction study and scanning electron microscopy.

- The in vivo pharmacokinetic study of SD-15 is performed using non-compartment analysis by linear trapezoidal method. 